\title{
The Streaming Service Under Pandemic with the Example of Performance of Disney+
}

\author{
Yaqi Jia ${ }^{1, *}$ \\ ${ }^{1}$ University of Toronto, Rotman Commerce, Toronto, Canada \\ *Corresponding author. Email: yaqi.jia@mail.utoronto.ca
}

\begin{abstract}
Today, most people cannot live without streaming services especially in the Big data age. These streaming services bring us to a more convenient, effective, and wonderful world. Observations for the performance of the streaming service under pandemic with the example of the performance of Disney+ which is a streaming platform created during the pandemic. This paper uses online data to analyze these performance. These streaming services increased the financial situation of their company and Disney+ helped Disney during the hard period. This paper will analyze how the streaming services are able to influence the world potentially.
\end{abstract}

Keywords: pandemic, streaming service, Disney+

\section{INTRODUCTION}

More and more modern people start to use streaming service to watch videos, read articles, and so on. The specialty of streaming service became especially obvious during the pandemic, when almost all the other business service and products are facing unavoidable large loss. These streaming service connected people with each other and become the most popular working and playing way during the pandemic. During the pandemic, without leaving room, people can know what happen around the world and how does the pandemic go. They can also make small videos and post out to the public space to share their mood.People also experience a hard time to live such as buy clothes and food they want, but streaming services also give them the chance to do these necessary activities online.

This paper will focus on how the world is changed by the streaming service during the pandemic and with the example of how Disney+, one of the streaming service created by Disney, influence the stock price on Disney. This gives a clearer picture of the importance of streaming service during the pandemic.

\section{ANALYSIS}

\subsection{Overall view of streaming services}

COVID-19 has made winners of some industries and losers of others. Among the biggest losers, of course, have been restaurants, live music venues, the travel sector, and the meeting industry, all of which have had to cease or seriously scale back their operations during the pandemic in the interest of public health. Only now, with multiple vaccines in hand, is relief on the horizon. However, while some industries are in trouble, others are booming. One of the biggest winners has been streaming media-television shows, movies, and video games broadcast on-demand to their screens, 24/7.[1]

For more than a year, people all over the world have been taking refuge in places with nowhere to go and nothing to do. For many of them, their only advantage is their high-speed Internet connection and cloud, which makes it possible to access work, friends, and entertainment through streaming video in new ways. However, in the past year, discerning consumers faced with a dizzying array of choices have focused their attention on which platforms are suitable for them - and which platforms are not suitable for them. In 2020, as more streaming media platforms try to open up space for themselves in niche categories, competition in an already saturated market will become more intense. The streaming media ecosystem is now clearer than ever. For example, as more and more people use video conferencing to connect with colleagues and relatives, Zoom has flourished. However this is only the tip of the iceberg of streaming video. Streaming services such as Netflix, Hulu, Disney+, Apple TV+, NBC's Peacock, and HBO Max have become a reliable way to alleviate 
isolation and boredom, while the live broadcast platform Twitch is a godsend for online gamers.

Parallel to the pandemic, there have been numerous streaming video services launched by such major studios as Disney, Universal, and Warner Bros, with Netflix NFLX $+0.5 \%$, Hulu, and Amazon AMZN -0.7\% joining and competing. By 2020, revenues for digital entertainment will be $\$ 61.8$ billion, a $31 \%$ increase over 2019. In terms of theatrical and home entertainment revenue, digital media accounted for more than three quarters. Since 2019 digital revenue has increased by $82 \%$, compared to $55 \%$ in 2020 . In 2020 , digital revenue is expected to account for $82 \%$ of revenue from theatres, TVs, and mobile.(Adgate, 2021) There is a report Nielson published in April 2020 that stated that streaming video time from services such as Netflix, YouTube, Hulu, and Amazon Prime Video more than doubled compared with a year ago (Streaming services have accelerated during COVID-19. will this continue?, n.d.).

In fact, Americans spent 44\% more time streaming media in the fourth quarter of 2020 than they did in the fourth quarter of 2019, streaming media intelligence company Conviva reported in its most recent "State of Streaming" report [1].

The average American uses 3.6 streaming services, according to a Harris survey in the Wall Street Journal in late 2019. This number can be observed to continue to rise as the streaming market expands to include new models such as subscription video on demand, advertising video on Demand (AVOD), transactional Video on Demand and now high-end video on Demand accessed through Disney + 'where people can watch movies for a limited time. (Streaming trends in Canada are like those in the United States, with "approximately $41 \%$ of Canadians using a streaming TV service daily", according to a 2020 report by market data firm Statista.) This highly fragmented model confuses and confuses consumers, but also presents opportunities and challenges for multi-video platform devices like YouTube TV or top-tier devices like Apple TV, Roku, and Amazon Fire. These companies now have to figure out how to integrate this market and make money from the simplicity of their products and one-stop shopping.

To make matters even more complicated, during the COVID-19 pandemic, live sports took a break and more athletes and sports supporters played video games in their free time, with video games and sports experienced significant growth during the preceding period. Global broadcast hours for Twitch almost doubled in the second quarter to 5 billion hours, according to Streaming Data Analytics Company Stream Hatchet Streaming platforms and services are not only competing with one another, they are fighting for the free time as well.
Global streaming consumption has continued to soar, states the report, the results of which are included in companies' own data. Netflix, for example, reported attracting 15.77 million new subscribers in Q1 2020, a $23 \%$ increase over the same period in 2019 . At the end of last year, there were over 200 million globally paid members, 37 million of whom accepted the service in 2020 , including 8.51 million in the last quarter alone [1].

However, most of these streaming services have not yet been cost-effective, but their losses are well below what they were a year ago. Direct to Consumer revenues were up $73 \%$ to $\$ 3.5$ billion, while operating losses were down from $\$ 1.1$ billion to $\$ 466$ million. The company stated that it does not expect Disney+, Hulu and ESPN+ to make a profit until 2024. Revenue at Disney Media and Entertainment Distribution fell 5 per cent to $\$ 12.7 \mathrm{bn}$, while operating income fell 2 per cent to $\$ 1.45 \mathrm{bn}$ [1]. Among the company's other divisions are its streaming and movie business, and its television and movie licensing business. Despite the impact of Coronavirus on Walt Disney Co.'s profits, Disney +'s popularity reduced the pain. This achievement enabled Disney to comfortably beat Wall Street's waning expectations, allowing the company to boost its stock price. For the quarter ended Jan. 2, the home-entertainment giant reported adjusted earnings of 32 cents per share, down from $\$ 1.53$ a year earlier. This marks a significant drop for the company, but not the loss investors anticipated. As a result, Disney's revenue decreased 22 percent from \$20.9bn to $\$ 16.2 \mathrm{bn}$. Disney made a profit of $\$ 17$ million in the fourth quarter, which is still a modest improvement over $\$ 2.1$ billion a year earlier, but still significant. in the same period a year earlier [1].

\subsection{Exampled with Disney+}

A spokesperson for COVID-19 gave a statement saying that the new rule caused theme parks to close, cruise lines to disrupt operations, Broadway shows to stop, and movie theatres to close. An estimated \$2.6 billion in operating income was lost due to the closure, resulting in deeply painful conditions for the families affected. Though some setbacks have been experienced, Disney has managed to weather these disruptions, and its share price has continued to climb to record levels despite delays in film releases and parks that are closed or sparsely visited. Investors remain focused on the strong growth of its streaming services, particularly Disney Plus. As of January of this year Disney+ members have reached 100 million subscribers after launching its streaming service in November 2019 that includes Marvel, Pixar, National Geographic, Disney and more. Despite Disney's prediction that it would take five years to reach 90 million subscribers, its rapid acquisition of paying subscribers has stunned analysts and even Disney. 
Disney+ was the clear winner in the streaming competition except for Netflix in its first year. As outlined in the company's earnings release, revenue of $\$ 14.7$ billion exceeded analysts' expectations of $\$ 14$ billion, while earnings per share were down 20 cents versus expectations of 70 cents. In December 2020, 86.8 million users were on the platform, a number that increased to 94.9 million the next quarter [5]. In addition to the second season of The Mandalorian, Disney has credited streaming service on becoming an attractive platform for new subscribers. With Disney's multiple services such as ESPN Plus and Hulu, all together, it has 146 million subscribers.

On revenue of $\$ 15.92$ billion, analysts expected a loss per share of 38 cents, and over 90 million users are expected to subscribe to Disney+. According to Disney's latest statement, its streaming service now has nearly 95 million subscribers, compared to 86 million in December of 2020 [1]. Moreover, Disney's (NYSE:DIS) CEO also announced that its streaming business debuted with 146 million paid subscriptions at the end of the third quarter, which includes services like Hulu, Hotstar, ESPN+ and more. Its stock rose 3\% after hours following the release of its earnings [3].

The earnings report presented by Disney on Thursday was mostly predictable, and it further highlighted the importance of Disney+ to the company's health. In after-hours trading on the report, Disney shares rose about 3 percent before settling slightly lower.

Despite all its challenges, Disney has not giving up on its parks, so Chapek emphasized that it was working on new global attractions themed to "Ratatouille", "Guardians of the Galaxy", and "Zootopia". Likewise, the hiatus has also caused the company to consider ways to boost its productivity.

We believe streaming is heading towards a bright future due to the fact that streaming still remains the primary distribution platform and delivery method for content to homes and devices. Price has become more important for consumers now that there are so many options available, and this is why AVODS have increased in number to help offset the costs for consumers. Since Avods such as Roku TV, Pluto TV, and Crackle have demonstrated their success, we can expect this model to continue to grow.

There is also a great opportunity for reaggregation for a corporation in the streaming space in the face of market saturation. Due to consumer acculturation, the more unified and straightforward the solution, the higher the likelihood of grabbing their attention. The demand for MVPD subscriptions has decreased significantly over the past year, so we expect to bundle and bundle services more effectively as well as offer more affordable prices. Furthermore, the significance of data and algorithmic models are expected to grow in the future. These patterns determine whether a platform can entice users to click on the next video, song, or movie recommendation, thereby extending their engagement time. These recommendation engines will become an important means of generating traffic in the short term. Despite streaming being an over saturated market consumers are not likely to abandon streaming anytime soon. As traditional media and traditional broadcasters enter the digital transformation era and be able to success in their digital transformation journey, they must understand streaming and how it fits into their transformation strategies. Streaming has become an integral part of the media landscape and traditional broadcasters need to have more understanding of these trends in order to successfully integrate them into their digital transformation journey. In an era where consumers' time is being consumed by an increasing number of platforms, it is vital to think about strategies for how to capture and retain their interest. Digitally absent companies ought to check out the opportunities found on these platforms. As for Disney + , although it has immense popularity this year, it still needs a lot of effort before it can become profitable. "Moffett Nathanson, a media research firm, estimates that Disney + will likely lose $\$ 2$ billion to its parent company this year and another $\$ 2.2$ billion in fiscal 2021" [2]. Disney expects its services to become profitable in the fiscal year 2024. Media analyst Michael Nathanson of Moffett Nathanson also stated that Disney+ and the rest of Disney's direct-to-consumer assets like ESPN+ and Hulu are the most important assets in terms of investors' eyes, according to CNN Business. "It is a source of long-term growth and offsets (factors like cord-cutting and shifting audience behavior). Following the announcement that Disney+ has now surpassed its own goal of having 100 million subscribers since November 2019, Disneyt has achieved something of a breakthrough. Achieving the same subscriber number has taken Netflix NFLX $+1.4 \%$ ten years. Amazon AMZN $+1.9 \%$ Prime Video, which competes against rival streaming services, has 147 million global subscribers, while rival streaming services have 203.7 million subscribers. According to Disney, as it is on the rise in streaming, it is targeting 260 million subscribers by 2024 . Furthermore, a whopping $\$ 15$ billion has been earmarked for Disney's content budget [5].

In comparison to last year, Disney has said it expects to add more than 100 new titles to the service annually. Getting more subscribers will be greatly facilitated through this. Since launching, Over 4,500 hours of content are available on Disney+, while Netflix has 40,000 hours and Amazon has 50,000 hours. Richard Broughton, an analyst at Ampere Analysis, believes that Walt Disney DIS $-2.6 \%$ will dominate the streaming wars [5]. "Disney+ has proven itself to be one of the fastest growing subscription video services in the world; 
congrats to them for becoming such a global force so quickly". The fast growth and milestone achievement of Disney+ was unprecedented when it is still only half the size of Netflix, said Broughton. In addition to a robust schedule of content throughout the rest of 2021, Disney + boasts a wealth of new programming that will inspire customers to renew their subscriptions. The additional content calendar for Phase 4 with new Marvel series like The Falcon, The Winter Soldier, and Loki, in addition to Star Wars, is sure to attract new subscribers, especially those who were not big fans of Star Wars and were awaiting the opportunity to be immersed in $\mathrm{MCU}$ again.

\section{CONCLUSION}

All in all, Disney+ and streaming market gain a lot in their development through this pandemic. The paper also uses specific datas to identify how the streaming services and these large studios including Netflex, Youtube, Amazon, Hulu, and so on, quickly catch up their market and gain larger subscriber, and even company like Disney follow this tendency to put their attention on Disney+ and succeed. In detail, these streaming services not only gain a lot of profit and provide unprecedented convince for people during pandemic, but also kind of change people's lifestyle, as mentioned that they quickly become the three quarters' of peoples's spending on average, and people might depend on streaming services even more in their future after pandemic. The pandemic although bring lots of damage in health and in-person services, it motivate the development in online streaming services and entertainment company, allowing the streaming services works more in more people's daily life. There are larger market and advanced capital holding for streaming services with more chances to explore more potential money-making project and their future direction.

To improve this article and make the more meaningful research, it is possible to research more on people's behaviour after this pandemic. Although this pandemic give these streaming services a chance to prepare and expand their probable future profits, some fluctuation might happen as well. Will people delete some subscription they have made during the pandemic after the covid-19 end? Will this lead to a decline of company focusing on streaming services facing a shock, are cord-cutting and cord-shaving happen after the pandemic? How serious would some after events might happen and how much would this influence on the current profitable landscape? (New cord cutting insights amidthe covid-19 pandemic, n.d.)

\section{AUTHORS' CONTRIBUTIONS}

This paper is independently completed by Yaqi Jia.

\section{ACKNOWLEDGMENTS}

I have been helped a lot from the professor, families and the online information. Sincerely, thanks for all these helpers.

\section{REFERENCES}

[1] Adgate, B. (2021, April 13). The impact covid-19 had on the entertainment industry in 2020. Forbes. Retrieved September 18, 2021, from https://www.forbes.com/sites/bradadgate/2021/04/1 3/the-impact-covid-19-had-on-the-entertainment-in dustry-in-2020/?sh=65328297250f.

[2] Lang, B. Disney earnings beat Expectations thanks to STREAMING GROWTH. Variety, February 12, 2021.

https://variety.com/2021/biz/news/disney-earningsdisney-plus-streaming-1234906441/.

[3] New cord cutting insights amidthe covid-19 pandemic. New Study: Cord Cutting During Coronavirus | Roku Advertising. (n.d.). Retrieved September 18, 2021, from https://advertising.roku.com/resources/guides-repor ts/cord-cutting-in-uncertain-times.

[4] Pallotta, F. Disney+ was the FUTURE. now it's Disney's present. November 12, 2020. CNN. https://www.cnn.com/2020/11/12/media/disney-an niversary/index.html.

[5] Pallotta, F. Disney is still getting hammered by the pandemic, but Disney+ remains a star, February 11, 2021

CNN. https://www.cnn.com/2021/02/11/media/disney-ear nings-q1-2021/index.html.

[6] Streaming services have accelerated during COVID-19. will this continue? RBC Wealth Management. (n.d.). Retrieved September 18, 2021, from https://www.rbcwealthmanagement.com/us/en/rese arch-insights/streaming-services-have-acceleratedduring-covid-19-will-this-continue/detail/.

[7] Video streaming industry growth and future of Cloud-Enabled Streaming. The Forecast By Nutanix. (n.d.). https://www.nutanix.com/theforecastbynutanix/tec hnology/will-the-streaming-video-bubble-burst-pos $\mathrm{t}$-pandemic.

[8] Zeitchik, S. Disney's profits plummet As CORONAVIRUS keeps its core businesses flailing. The Washington Post, November 13, 2020. https://www.washingtonpost.com/business/2020/11 /12/disneys-profits-plummet-coronavirus-keeps-itscore-businesses-flailing/. 